\title{
Narrativas sequenciais em destaque: um estudo sobre o gênero HQtrônica e sua dinâmica em sala de aula
}

\author{
Narrativas secuenciales destacadas: un estudio sobre el \\ género HQtrónica y su dinámica en el aula
}

\section{Narratives sequences in focus: a study about the HQtronic genre and its dynamics in the classroom}

\author{
Cássia Vanessa Batalha* \\ Renan Luis Salermo**
}

\begin{abstract}
RESUMO: Circunscritos ao universo de ensino-aprendizagem de Língua Portuguesa e apoiados numa perspectiva metodológica de cunho teórico-especulativa, colocamo-nos a discutir sobre o gênero HQtrônica, mais especificamente sobre a obra "Diário de Vírginia", de Cátia Ana, com vistas a propor uma sequência de atividades focada na leitura para alunos do primeiro ano do Ensino Médio. Para tanto, mobilizaremos como referencial principal os preceitos de Bakhtin (2003), Buzato et al (2013), Cope e Kalantzis (2009), Lévy (1996, 1999) e Rojo (2012, 2013), evidenciando, em nosso corpus, os aspectos acerca da multimodalidade, da multiculturalidade, da hipertextualidade, da interatividade e da interdisciplinaridade com a arte.
\end{abstract}

PALAVRAS-CHAVE: HQtrônica; Leitura; Ensino-Aprendizagem de Língua Portuguesa.

RESUMEN: Circunscrito al universo de la enseñanza-aprendizaje de la lengua portuguesa y apoyado por una perspectiva metodológica de carácter teóricoespeculativo, nos ponemos a discutir el género o HQtrônica, más específicamente en la obra " Diario de Virginia" de Katie Ana, con el objetivo de proponer una secuencia de actividades enfocadas en la lectura para alumnos de la Enseñanza Secundaria. Para eso, movilizamos como referencia principal los preceptos de Bakhtin (2003), Buzato et al (2013), Cope y Kalantzis (2009), Lévy (1996, 1999) y Rojo (2012, 2013), evidenciando, en nuestro corpus, los aspectos acerca de la multimodalidad, de la multiculturalidad, de la hipertextualidad, de la interactividad y da interdisciplinaridad con el arte.

PALABRAS CLAVE: HQtrônica; lectura; Enseñanza-Aprendizaje de portugués.

\footnotetext{
* Doutora em Estudos da Linguagem pelo PPGEL-UEL - Universidade Estadual de Londrina. Professora de Português - Boituva. cassiabatalha@bol.com.br

** Doutorando do PPGEL - Programa de Pós-Graduação em Estudos da Linguagem da Universidade Estadual de Londrina (UEL). renanlsalermo@hotmail.com
} 
ABSTRACT: Confined to teaching universe / learning Portuguese and supported in a methodological perspective of theoretical and speculative nature, we put ourselves discussing the HQtrônica genre, more specifically on the book "Diary of Virginia" by Katie Ana, with a view to proposing a sequence of activities focused on reading for first year students in high school. In order to do so, we will mobilize as main reference the precepts of Bakhtin (2003), Buzato et al (2013), Cope and Kalantzis (2009), Lévy (1996, 1999) and Rojo (2012, 2013), showing in our corpus the aspects of multimodality, multiculturalism, hypertextuality, interactivity and interdisciplinarity with art.

KEYWORDS: HQtronic; Reading; Teaching-Learning Portuguese.

\section{Introdução}

O homem está condenado aos seus espaços e seus tempos. E nesse enquadramento histórico, temos a linguagem como ferramenta ardilosa de significá-lo no mundo, de acordo, é claro, com suas vivências. Todavia, tal pressuposto não é garantido e considerado nos espaços destinados ao aprender, uma vez que, grosso modo, continuamos a perpetuar os paradigmas tradicionais e competências que, como bem pontua Lévy (1999, p. 159), estarão obsoletas ao longo do percurso profissional das pessoas. E como lidar com tal constatação? Como redefinir outros cenários? Como potencializar um ambiente de aprendizado com tarefas e ferramentas "relativamente novas", redesenhando, de fato, uma proposta que contemple as unicidades das temáticas e das estruturas dos artefatos digitais?

É nessa direção que nos dispomos a buscar caminhos e tentativas para minimizarmos os vazios recorrentes entre os universos de leitura experimentados pelos jovens estudantes e aqueles preconizados pela escola. Por esse motivo, com o intuito de elaborar uma sequência de atividades concentrada em subsidiar e amparar práticas de leitura mais próximas e situadas para alunos do primeiro ano do Ensino Médio, dedicamo-nos a explorar a HQtrônica "O diário de Virgínia", concebida pela quadrinista Cátia Ana, desde o ano de 2010. Não é objetivo atestar e garantir o "ineditismo" do gênero hipermidiático escolhido, mas sim lançar mão de uma possível estratégia de 
ação que leve em conta os aspectos multimodais, multiculturais, hipertextuais, interativos e interdisciplinares presentes em nosso corpus.

\section{Referencial Teórico - Redesenhando Conceitos}

Muito se diz sobre o potencial transformador das tecnologias na sociedade, ainda mais nos espaços escolares, onde se tornaram uma espécie de apogeu. Essa premissa em torno do entusiasmo entre jovens e a mídia digital são essenciais, mas apenas na medida em que se tem a ideia de que sua manipulação é empoderadora e que, em certos aspectos, promove estilos mais espontâneos, fluídos e informais de aprendizagem. Por esse motivo, direcionamos olhos atentos às tecnologias digitais, pois permitem o acesso a um oceano todo de intenções que se movem e se transcodificam permanentemente. Evidente que a totalidade não é, em suma, obtida, mas delineada parcialmente, à sua maneira, de acordo com os critérios de pertinência de seus usuários. $E$ isso nos faz pensar na relevância em descobrir como os leitores processam os diferentes tipos de informação e como integram, aos seus saberes, as informações que vão sendo acessadas. Apoiando-nos em Lévy (1999), ao estabelecer relações entre a Educação e suas outras roupagens com o saber, via cibercultura, consideramos, então, a opção por espaços de leitura emergentes, abertos, contínuos e não lineares, que incentivem uma inteligência coletiva.

Quando discutimos sobre leitura, é essencial o tratamento do conceito de hipertextualidade. Lévy (1996, p. 40) defende que "o hipertexto é uma matriz de textos potenciais realizados na interação com o usuário". Sob essa perspectiva, toda leitura seria hipertextual, independente de sua realização ser ou não linear. E seu caráter inovador, a rigor, se fundaria apenas quando fundido ao novo suporte tecnológico, que permite aí uma nova forma de textualidade. Os recursos de intertextualidade explícitos ou implícitos, mobilizados no processo de leitura, seriam, nestes moldes, uma das maneiras 
possíveis, por exemplo, de ativarmos o texto-fonte, atualizando os trajetos e repertórios pessoais.

Outra associação que deve ser observada com muito cuidado é a de que toda atividade de linguagem migrante para a web é, em essência, um novo gênero. Poderíamos dizer que o mais conveniente para o caso é a noção de misturas de padrões genéricos coocorrentes entre os gêneros textuais, decorrentes de reelaborações, "como aquelas que emanam de possíveis criações de um gênero com inclinação estandardizada" (ARAÚJO; VASCONCELOS, 2011, p. 11). Acrescentando os postulados de Marcuschi (2002), entenderíamos esses gêneros vindos à tona como "projeções de outros com contrapartes prévias", sugerindo até a possibilidade de que os designers de softwares utilizariam padrões pré-existentes como alicerce para a moldagem de seus programas. A transmutação, definida por Bakhtin (1979), serviria para conceituar o processo pelo qual um gênero é capaz de assimilar outro, gerando assim o surgimento de formas genéricas híbridas ou mesmo novos gêneros. Para o teórico, a justificativa para o fenômeno da transmutação estava fundamentada na complexificação das esferas discursivas, o que fazia surgir novos enquadramentos enunciativos com 0 intuito de satisfazer as necessidades comunicativas impostas pelas práticas de linguagem. Tal interconexão passa a exigir habilidades e competências localizadas e atualizadas sócio-historicamente dos usuários, forçando-os ao arranjo e rearranjo de estruturas já manuseadas em outras situações.

Nosso corpus seria uma ilustração do caso. Além disso, teríamos como exemplo de transmutação o remix e o mashup, procedimentos operacionais, que "são aparentados da colagem e da montagem, técnicas extremamente férteis de criação de novos objetos a partir de outros já existentes" (BUZATO et al 2013, p.1198), também presentes em "O diário de Virgínia". Fontes":

- Disponível em: <www.odiariodevirginia.com>. Acesso em: 21 jul. 2016.

\footnotetext{
${ }^{1}$ Por uma questão de direitos autorais, optamos pelo uso dos links em destaque.
} 
- Disponível em:

<noticias.universia.com.br/destaque/noticia/2014/02/12/1081541/surrealism o-autorretrato-com-macaco-frida-kahlo.html>. Acesso em: 21 jul. 2016.

- Disponível em: <universosdarte.blogspot.com.br/2011/04/moca-com-brincode-perola.htm>. Acesso em: 21 jul. 2016.

- Disponível em: <noseahistoria.wordpress.com/os-alunos-e-a-historia2/mona-lisa/>. Acesso em: 21 jul. 2016

Neste interím, temos a interatividade. Traço mais promovido, defendido e pleiteado, atualmente, nos ambientes formais do saber. O status polifônico inerente aos novos meios com que convivemos, pode estabelecer uma comunicação unidirecional, mas também pode invocar a participação do público, ou mesmo prever uma autoria compartilhada. Nessa medida, teríamos uma prática otimizada se optássemos para a multiplicidade de vozes enunciadas e/ou uma interlocução livre, não mediada e aberta à expressão da coletividade, com vistas, como conceitua Silva (1998), à hiper-interação que funde a participação e a intervenção. Mas o primeiro tabu a ser quebrado sobre o tema seria a desmistificação do adjetivo interativo. Segundo Silva (1998), há muitos enganos em torno da designação interatividade, pois lidamos com o conceito de interação e o relacionamos indevidamente, confundido-o e até banalizando-o. Vale ressaltar que nenhuma ação humana ou social existe ou existirá desvinculada da interação. Contudo, a interatividade propõe uma ação dialógica entre o homem e a técnica, situando-o em um labirinto compositivo que pode subjugá-lo em qualquer instante na sua determinação de prosseguir em suas práticas de acesso ao meio ou à informação².

Foram esses os motivos que nos levaram ao "O diário de Virgínia". Seus contornos interativos, que solicitam outros muitos textos, determinados em um modelo de gênero reconhecível, mas pouco explorado em suas originalidades, nos disponibilizam um terreno fértil, particularmente, se pensarmos a respeito

\footnotetext{
2 Silva (1998) ainda destacada que a apropriação e alastramento do conceito "interatividade" pode ter surgido com a pop art ou "antiarte", de Hélio Oiticica, que promovia o "participacionismo" do público em manifestações artísticas nos anos 1960. Assim, entenderíamos que tais práticas não podem ser consideradas como "novas" ou "inéditas" em tempos integrados aos computadores, por exemplo.
} 
da abordagem dos temas. Isso porque elegemos como primordial a ideia de lidarmos com os multiletramentos emergentes na sociedade contemporânea, buscando incluir, em nossas atividades, a grande variedade de culturas presentes nas salas de aula, muitas vezes, submetidas pela intolerância com a alteridade.

Tais problematizações já eram salientadas, em 1996, pelo Grupo de Nova Londres que se colocou a confeccionar um manifesto com o intuito de priorizar a multiculturalidade em detrimento da cena unidirecional e, de certo modo, elitista, contemplada vez em vez nos ambientes institucionalizados como o locus do saber. As objeções do grupo se fundavam em colocações que visavam à apropriação das vozes das mulheres, indígenas, imigrantes e outras muitas identidades esquecidas ou mal representadas nos espaços escolares. Seus argumentos apontavam para dois vértices, o primeiro fundamentado na multiplicidade cultural das populações, essencialmente as urbanas, e a outro assentado na multiplicidade semiótica dos textos por meio dos quais nos informamos e nos comunicamos. Desse modo, deixaríamos de lado as oposições e antíteses culturais semeadas à nossa volta e adotaríamos uma abordagem de desessencialização das dicotomias canônicas e dominantes por uma atenta e preocupada com o hibridismo, com o sincrético. Abordagens estas repletas de escolhas politizadas para produções atuais, elegidas mais democraticamente e criteriosamente por nossos próprios alunos.

Sendo assim, não teríamos mais os letramentos, pois haveria em tudo a multiplicidade materializada, inclusive, nas diferentes ferramentas, como por exemplo: o áudio, as imagens, a diagramação, a formatação das fontes, além das já conhecidas: papel, lápis, giz e lousa. E nesses termos, teríamos também novas práticas de produção e recepção, que seriam condicionadas pelas roupagens presentes nos contextos. $\mathrm{E}$ as posturas consideradas mais "tradicionais" demonstram-se fraturadas, transgredidas. 0 engajamento nessas discussões otimizaria a possibilidade de abordar de forma eficaz a complexa realidade vivenciada por nós, professores, nas escolas. Além de projetar possibilidades para novas áreas de investigações nas quais o objetivo maior 
seria experimentar e rearranjar os enquadramentos elencados, redesenhando os próximos atos no campo da Educação. Para tanto, devemos sublinhar que os agentes sociais dessas mudanças, professores e alunos, são participantes ativos e protagonistas dos "futuros sociais".

\section{A Hqtrônica na Web: $O$ Diário de Virgínia em Análise}

Como exposto anteriormente, a configuração de alguns gêneros que circulavam fora do ambiente virtual, quando transmutados para este novo espaço, alteraram-se devido à potencialidade de exploração permitida pelo suporte. Essas mudanças direcionadas às histórias em quadrinhos se deram já em sua nomeação. Sua designação HQtrônica deixa pistas sobre a manutenção de características do gênero $H Q$, somando-se às especificidades do ambiente eletrônico. Os balões de fala, expressão genuína dos quadrinhos, por exemplo, são características preservadas na versão eletrônica. Em contrapartida, o dinamismo de virtualidades só é possível nesse nosso enquadramento tecnológico.

As Hqtrônicas são gêneros cada vez mais produzidos pelos novos e antigos quadrinistas, que antes executavam trabalhos somente no papel. Além da criação, a recepção na rede também é transformada. Ela exige leitores ativos e colaboradores, traço típico da cultura participativa e colaborativa da internet. Aliada à colaboração, a diagramação dinâmica do gênero é outro aspecto que convida o leitor a passear pelas telas das $H Q$ s. A exploração criativa da diagramação da HQtrônica pode ser igualmente vigorosa de significação como o momento de sua recepção pelo leitor. O dinamismo característico do ambiente hipertextual é fomentado pelos hqtronistas chegando num refinamento da linguagem nas $H Q S$ digitais.

Segundo Franco (2012), as propriedades das Hqtrônicas são: interatividade; animação; multilinearidade; trilha/efeitos sonoros; tela infinita; diagramação dinâmica. $O$ estudioso afirma ainda que, atualmente, há um 
cenário forte de produção das HQtrônicas no Brasil; exemplo desse refinamento estético é a produção da quadrinista brasileira Cátia Ana, autora da Hqtrônica "Diário de Vírginia", disponível em: <www.odiariodevirginia.com>.

"O diário de Virgínia" é uma webcomic produzida desde 2010. A publicação da história acontece em capítulos. São narrativas curtas que contam desejos, sonhos e anseios da personagem no universo feminino. 0 capítulo 21 é a Libertação! A escolha do episódio se deu por apresentar as inovações da Hqtrônica e por ser um dos capítulos que mais potencializam a interação do leitor.

No episódio selecionado, a narrativa é o desejo de Virgínia de se libertar dos estereótipos e imposições sociais que cabem à mulher. As roupas, a obrigatoriedade do curso superior, do amor e do casamento são alguns dos temas abordados pela narrativa, principalmente as limitações e impedimentos que os temas ocasionam na vida da protagonista que deseja o contato com a arte e a libertação. É forte a presença das imposições sociais nas roupas que devem ser encaixadas sobre a protagonista. Ao rolar a barra de rolagem verticalmente, os trajes culturais femininos ocidentais vão ficando disponíveis para que o leitor construa os estereótipos sociais.

A temática feminista que está presente no discurso dos quadrinhos de Cátia é pauta necessária para o ensino de Língua Portuguesa dentro da formação de cidadãos críticos e reflexivos, como direcionam os trabalhos de Kalantzis e Cope (2006) e Rojo (2013) e outros tantos documentos oficiais que reivindicam abordagens transversais. "O "pluralismo-cívico" é uma necessidade de coesão pela diversidade, comprometer-se com o papel cívico e ético das pessoas, o que, certamente, envolve letramentos críticos" (ROJO, 2013, p.17).

Considerando vozes que circulam na internet, a produção de Cátia Ana constrói um ethos enunciativo libertário. Dentro dessa nova prática de construção multiletrada, a quadrinista configura e dá voz para a produção feminina, possibilitando um discurso multicultural, favorecendo um hibridismo cultural característico da alta modernidade. Sobre o assunto, Rojo (2013) ainda complementa: "[...] a produção cultural atual se caracteriza por um processo de 
desterritorialização, de descoleção e de hibridação que permite que cada pessoa possa fazer 'sua própria coleção', sobretudo a partir das novas tecnologias" (ROJO, 2013, p.18). É nesse sentido que o conteúdo temático do episódio enfatiza a prática da descoleção, associando às obras da cultura erudita às obras de cultura de massa. Aliás, vale lembrar que as próprias histórias em quadrinhos, que hoje ganham espaço nas livrarias e universidades - cultura erudita -, é proveniente da cultura de massa.

Dessa maneira, é na alteração do contexto de circulação que o gênero se refaz, conforme os preceitos bakhtinianos. É sobre essa incidência e diálogos que a Hqtrônica se fortifica como um produto cultural desterritorializado, carregando a linguagem dos quadrinhos, o conteúdo temático variado e a forma composicional de artistas multimídias.

Aliado à composição dos gêneros numa desterritorialização, na cena em que há a escultura, há misturas entre os movimentos artísticos, Renascimento Italiano - Monalisa, Surrealismo Mexicano - Auto-retrato de Frida Kahlo e Barroco Holandês - Moça com brinco de Pérolas. A hibridação dessas referências e a reprodução por meio dos remix e mashups, também propiciadas pelo ambiente digital, é uma marca da linguagem da HQtrônica de Cátia Ana, competência exigida para a apropriação da significação. A polifonia artística preceituada por essa Hqtrônica é um dos aspectos do estilo e da forma composicional da artista visual que é aviventada pela circulação e produção na web 2.0.

A proposta de Cope e Kalantzis (2009) é de conceder mecanismos para a análise da dimensão multimodal dos textos construídos no ambiente digital. Nessa esteira, a produção dos quadrinhos na web, principalmente os vetores, que direcionam a narratividade, e as perspectivas de construção, que ancoram a iconização do real, são elementos que ajudam na significação da narratividade do gênero. Ou seja, os dois elementos do design visual proposto para os textos multimodais são que os que mais colaboram para a leitura de "O diário de Virgínia". 
Na obra, a projeção da categoria figura e fundo é um componente manobrado pelo enunciador logo no início da narrativa. Ao construir as principais imposições sociais (conclusão de curso universitário, roupas típicas femininas etc), a figura da garota na primeira tela torna-se fundo nas telas seguintes, nas quais as roupas são as novas figuras. É assim que as ocorrências, no momento da leitura, são organizadas, visto que as determinações da expressão dos quadrinhos corroboram para a articulação e sentidos da temática feminista na Hqtrônica.

\section{Em Diálogos com a Sala de Aula: Uma Proposta em (Re)ação}

A seguir, construímos uma sequência de atividades direcionada aos alunos do ensino médio para aula de leitura de textos multimodais, especificamente a interação e a construção do sentido em HQtrônicas. As atividades estão separadas em blocos temáticos que mobilizam conceitos de leitura do gênero próximos. Os títulos dos blocos informam os conceitos sobre o gênero que os alunos irão desenvolver após a conclusão.

\section{Atividades}

Trocando Ideias -- compreendendo possíveis discrepâncias e similitudes entre uma HQ e uma HQtrônica

O primeiro passo para a realização das atividades seguintes é uma análise atenta do site: <www.odiariodevirginia.com>, com os recursos tecnológicos disponíveis mais facilmente por você, como seu celular, tablet, notebook ou mesmo a sala de informática de sua escola.

Depois da consulta à HQtrônica, observe o link indicado e discuta com seus colegas as questões apresentadas abaixo:

Disponível em:<http://www.culturamix.com/humor/tirinhas/tirinhas-mafalda/>. Acesso em: 21 de jul. 2016.

1. O que acharam dos textos (Hqtrônica e as outras tirinhas)? Essas 
seriam as opções de vocês quando pensam em história em quadrinhos? Determine critérios que os qualifiquem positivamente ou negativamente.

2. Na opinião de vocês, por que agrupamos esses textos? Quais são as semelhanças e as diferenças compartilhadas e apresentadas pelos textos selecionados?

\section{O que são HQtrônicas?}

"[...] a definição do que nomeei HQtrônicas inclui efetivamente todos os trabalhos que unem um (ou mais) dos códigos da linguagem tradicional das HQs no suporte papel, com uma (ou mais) das novas possibilidades abertas pela hipermídia. A definição exclui, portanto, HQs que são simplesmente digitalizadas e transportadas para a tela do computador, sem usar nenhum dos recursos hipermídia destacados."

(Edgar Franco. Disponível em:

<http://www.anpap.org.br/anais/simposio2/pdf>. Acesso em: 21 jul. 2016.)

\section{Diversidades de Olhares -- Repensando a Multimodalidade e}

Multiculturalidade em "O Diário de Virgínia"

3. O que você pensa a respeito dos temas Feminismo e Identidade de Gênero, que aparecem na HQtrônica? Convidamos vocês, agora, ao estudo desses assuntos. Inicialmente, para auxiliá-los, recomendamos que assistam aos vídeos sugeridos e, depois, façam sua própria pesquisa, buscando fontes de sua preferência.

Vídeo 1 - Orientação Sexual e Identidade de Gênero, de Drauzio Varella: Disponível em: <https://www.youtube.com/watch?v=iXGCBNBUxi0>. Acesso em: 21 jul. 2016.

Vídeo 2 - Feminismo e Transformações Sociais, de Márcia Tiburi: Disponível em: <https://www.youtube.com/watch?v=bNzJufpeeto>. Acesso em: 21 jul. 2016. 
a) Qual é a relação das temáticas suscitadas pelos vídeos com a HQtrônica "Diário de Virgínia"?

b) Quais elementos não verbais da história da HQtrônica estruturam as possíveis associações encontradas por você?

c) Sugiram aos colegas de classe um filme que trate diretamente acerca de qualquer um dos temas abordados, apresentando duas evidências baseadas nos textos que estão sendo discutidos e que sustentem a indicação.

4. Considerando as discussões e debates em torno dos temas propostos, já realizados em sala de aula, reelabore e reconstrua visualmente, em grupos, algumas das situações suscitadas na $H Q$ "Diário de Virgínia". Por exemplo, podem colaborar para a confirmação das imposições sobre a mulher na sociedade: as roupas e os bons modos femininos. Para a concretização da proposta, você poderá utilizar recortes de jornais, revistas ou seus próprios talentos artísticos.

\section{Ampliando os Saberes -- Intertextualidade e Hiperlink}

Intertextualidade:

Pensando Bem

- substantivo feminino

Rubrica: literatura.

1 superposição de um texto literário a outro

2 influência de um texto sobre outro que o toma como modelo ou ponto de partida, e que gera a atualização do texto citado.

Ex.: Mensagem, de Fernando Pessoa, apresenta i. com a épica camoniana

3 utilização de uma multiplicidade de textos ou de partes de textos preexistentes de um ou mais autores, de que resulta a elaboração de um novo texto literário.

4 em determinado texto de um autor, utilização de referências ou partes de obras anteriores deste mesmo autor.

HOUAISS (2012, p.446) 
5.Depois de uma leitura atenta da $H Q$ "Diário de Virgínia", você notou referências a outros textos já antes vistos por você?

a) Elenque e localize, individualmente, quais são e onde estão essas recorrências de outros textos que você já conhecia ou tinha apenas visto.

b) Agora, em duplas ou grupos, conversem e discutam as listagens das ocorrências que vocês já conheciam e quais os colegas já conheciam.

c) Por fim, pesquisem em outras fontes, como a internet ou livros, informações a respeito dos textos que vocês já conheciam e que apareceram novamente em O Diário de Virgínia. Depois, pensem: quais foram as alterações e manutenções que aconteceram nesses textos?

\section{Ao professor...}

Por meio de cada bloco da sequência de atividades, tentou-se evidenciar um elemento dos três que compõem o gênero discursivo para Bakhtin. No primeiro bloco, a estrutura da Hqtrônica e da $H Q$ fizeram parte das atividades; em seguida, o conteúdo temático é o elemento contemplado, por meio das discussões do feminismo e da necessidade do pluralismo cívico. Por fim, no terceiro e último bloco, o estilo do gênero, fortalecido pelo ambiente digital, é a temática desenvolvida.

\section{Algumas Conclusões}

Se o mundo significante é visual, sonoro, propriamente multimodal, por que não trazê-lo para nossas práxis pedagógicas? Foram essas as determinações que nos levaram ao "O diário de Virgínia". Nossos esforços buscaram ir ao encontro da explicitação e integração de suas recorrências e especificidades, isso porque, como já discutimos, uma época de multiculturalidade requer progressos em direção a uma pedagogia eficiente de leituras e produções de textos em seus complexos e atualizados sincretismos. 
Como demonstramos, a HQtrônica não é pronta e acabada, e há ainda a chance de o internauta imprimir o ritmo e a composição que acredita ser mais adequado a sua leitura ou navegação. Nesse caso, e a nosso ver, as vantagens mais importantes recaem sobre a decomposição da linearidade textual e sobre o protótipo de um leitor ativo, que pode se confundir com o autor, assumindo uma postura definitivamente dinâmica. Para o caso, como assinala Lévy (1996, p.42): "O texto continua subsistindo, mas a página furtou-se". Assim, é essencial ressaltar que temos muitas dificuldades para lidar com a interatividade, com o processo colaborativo, que são genuínos de uma concepção de linguagem interacionista, por exemplo. Assim, nossos desafios maiores não estiveram somente na abordagem do gênero em questão e, por consequência, no manuseio das novas tecnologias, mas sim, e principalmente, em lidar adequadamente com as práticas escolares de leitura de modo geral, uma vez que já eram e são restritas e insuficientes mesmo para a 'era do impresso'.

Nesse sentido, estão dispostos aí alguns possíveis encaminhamentos práticos e sugestões para uma análise da HQtrônica: "O diário de Virgínia", sob a justificativa de desmistificar uma mediação pedagógica que encare os textos multimodais apenas como vetores, suportes ou pretextos da linguagem verbal, em seus moldes mais formais e canônicos. Dessa forma, tentamos desafiar seus conteúdos temáticos e também suas qualidades sensíveis e plásticas, com o intuito de instrumentalizar as habilidades e competências de nossos leitores, instigando-os ao exercício da sensibilidade, da imaginação, da estratégia e da atualização, integrando-os, talvez, a outros paradigmas, mais praticáveis e significantes.

\section{Referências}

ARAÚJO, Júlio C.; VASCONCELOS, Lucas Lima de. Web 2.0 e as práticas de linguagem: novos gêneros?. Texto Livre: Linguagem e tecnologia; v.4, n.2, p. 11-14, 2011. Disponível em: 
<http://periodicos.letras.ufmg.br/indez.php/textolivre>. Acesso em: 21 jul. 2016.

BAKHTIN, Mikhail. Estética da criação verbal. Tradução Maria Emsantina Galvão G. Pereira. 2. ed. São Paulo: Martins Fontes, 1997.

BUZATO, Marcelo El Khouri et al. Remix, mashup, paródia e companhia: por uma taxonomia multidimensional da transtextualidade na cultura digital. $R B L A$. Belo Horizonte, v. 13, n.4, p. 1191-1221, 2013.

CAZDEN, Courtney; COPE, Bill; FAIRCLOUGH, Norman; GEE, Jim; et al.A pedagogy of multiliteracies: dessigning social futures". Harvard Educational Review.Spring: Research Library, p. 60, 1996.

COPE, Bill; KALANTZIS, Mary (Orgs.). Multiliteracies: Literacy Learning and the Design of Social Futures. New York: Routledge, 2006.

DA VINCI, Leonardo. Monalisa. 1503-1504. Óleo sobre tela. $77 \mathrm{~cm} \times 53 \mathrm{~cm}$. Paris: Museu do Louvre. Disponível em: <noseahistoria.wordpress.com/osalunos-e-a-historia-2/mona-lisa/>. Acesso em: 21 jul. 2016.

FRANCO, Edgar Silveira. HQtrônicas: do suporte papel à rede Internet. São Paulo: Annablume e Fapesp, 2008.

FRIDA, Kahlo. Self-portrait with Monkey.1938. Óleo sobre masonite. $40 \mathrm{~cm} \times 30$ $\mathrm{cm}$. Galeria de Arte Albright-Knox. Disponível em: $<$ noticias.universia.com.br/destaque/noticia/2014/02/12/1081541/surrealismoautorretrato-com-macaco-frida-kahlo.html>. Acesso em: 21 jul. 2016.

HOUAISS, Antônio. Dicionário Houaiss da língua portuguesa. Rio de Janeiro: Objetiva, 2012.

Jean Wyllys: orientação sexual e identidade de gênero. Disponível em: <https://www.youtube.com/watch?v=iXGCBNBUxi0>. Acesso em: 21 jul. 2016. LÉVY, Pierre. O que é virtual? Trad. Paulo Neves. São Paulo: 34, 1996.

LÉVY, Pierre. Cibercultura. Trad. Carlos Irineu da Costa. São Paulo: 34, 1999.

MARCUSCHI, Luiz Antônio. Gêneros textuais emergentes no contexto da tecnologia digital. 50a Reunião do GEL - Grupo de Estudos Linguísticos do Estado de São Paulo, USP, São Paulo, 23-25 de maio de 2002.

"O feminismo é para quem gosta de transformações sociais", diz a filósofa Marcia Tiburi. Disponível em: <https://www.youtube.com/watch?v=bNzJufpeeto>. Acesso em: 21 jul. 2016 
ROJO, Roxane Helena Rodrigues. Pedagogia dos Multiletramentos. In: ROJO, Roxane; MOURA, Eduardo. (Orgs.). Multiletramentos na Escola. São Paulo: Parábola Editorial, 2012, p. 5-19.

ROJO, Roxane Helena Rodrigues. (Org.). Escola conectada: os multiletramentos e as TDIC. São Paulo: Parábola, 2013.

ROJO, Roxane Helena Rodrigues. Gêneros discursivos, multiletramento e hipermodernidade. In: ROJO, Roxane Helena Rodrigues; BARBOSA, Jacqueline Peixoto. (Orgs.) Hipermodernidade, multiletramentos e gêneros discursivos. São Paulo: Parábola Editorial, 2015, p.7-20.

SILVA, Ana Cátia B. da. Diário de Virgínia. Disponível em: <www.odiariodevirginia.com>. Acesso em: 21 jul. 2016.

SILVA, Marco. O que é interatividade. Boletim técnico do Senac, Rio de Janeiro, v. 24, n.2, p. 27-35. maio/ago. 1998. Disponível em: <http://www.senac.br/informativo/bts/242/boltec242d.htm>. Acesso em: 21 jul. 2016.

Tirinhas da Mafalda. Disponível em:

<http://www.culturamix.com/humor/tirinhas/tirinhas-mafalda/>. Acesso em: 21 jul. 2016.

VERMEER, Johannes. Rapariga com Brinco de Pérola. 1665. Tinta a óleo. $44 \mathrm{~cm}$ x $39 \mathrm{~cm}$. Mauritshuis. Disponível em: <universosdarte.blogspot.com.br/2011/04/moca-com-brinco-de-perola.htm>. Acesso em: 21 jul. 2016. 